\title{
GENOTYPIC AND PHYLOGENETIC CHARACTERIZATION OF GIARDIA INTESTINALIS FROM HUMAN AND DAIRY CATTLE IN KAFR EL SHEIKH GOVERNORATE, EGYPT
}

By

\author{
SAID E. R. AMER \\ Department of Zoology, Faculty of Science, Kafr El Sheikh University, \\ Kafr El Sheikh, 33516, Egypt mssamer5@yahoo.com; \\ mssamer5@gmail.com
}

\begin{abstract}
Giardiasis is a wide-spread intestinal disease of both humans and animals, with no morphological distinction between different assemblages and/or genotypes. The present study aimed to demonstrate the molecular identity of Giardia intestinalis parasites in clinical samples collected from infected cases screened at commercial laboratories and neonatal calves at dairy cattle farms, in Kafr El Sheikh. Molecular analysis based on PCR-sequence of triose phosphate isomerase (TPI) gene fragment. Results reported herein indicated that assemblage A was detected in 18/48 human isolates $(37 \%)$ and $4 / 18(22.2 \%)$ of the animal derived isolates, with subassemblage AII was the predominant in human samples and AI in the animal isolates. Whereas assemblage B was the predominant assemblage in the human infections (32/48: 66.7\%), assemblage $\mathrm{E}$ was the major genotype in the animals samples (14/18: $77.8 \%)$. Genetic heterogeneity was pronounced feature in the generated sequences of all assemblages referring to wide diversity of Giardia population in Egypt. Also, results stressed the significance of neonatal calves as reservoir of zoonotic Giardia infections in human. Phylogenetic relationship of the analyzed isolates was inferred based on the reference sequences in the database.
\end{abstract}

Keywords: Egypt, Giardia, Assemblage A, Assemblage B, Assemblage E, Triose Phosphate Isomerase (TPI), Zoonosis.

\section{Introduction}

Giardia duodenalis (syn. G. lamblia \& G. intestinalis) is a cosmopolitan enteric protozoan that infects a wide range of vertebrates, including humans, livestock, companion animals or wildlife (Thompson and Monis, 2004; Thompson et al, 2008). Giardiasis outbreaks occurred worldwide (Karanis et $a l, 2007)$, but often the original source of contamination is not identified. Typically, infection is acquired after the ingestion of highly environmental resistant infective cysts (Feng and Xiao, 2011) by direct fecal-oral route or in contaminated food or water (Thompson, 2004; Tien and Earn, 2010; Plutzer et al, 2010). The parasite is recognized as a major etiologic agent of diarrhea in the infected hosts resulting in direct and indirect economic losses in 
animals (Aloisio et al, 2006) and health consequences in human (Heresi and Cleary, 1997; Chin et al, 2002; Troeger et al, 2007; Buret, 2008; Cotton et al, 2011; Ignatius et al, 2012). In the developing countries, children are at most risk from the clinical consequences of G. duodenalis infection, (Savioli et al, 2006; Mehraj et al, 2008), and may be implicated for retarded growth and reduced cognitive function (Fraser et al, 2000; Thompson 2001; Thompson and Monis, 2004). Giardiasis was described as a typical poverty disease, whereas compromised hygiene, sociodemographic conditions, contaminated environment and/or direct and frequent contact with the animals may contribute in the high prevalence $(\sim 50 \%)$ reported in the developing countries versus $\sim 5 \%$ in industrialized ones (Thompson, 2000; Thompson and Smith 2011; Santos et al. 2012). Studies concerned with the occurrence of Giardia in animals show pronounced differences from one to other (Becher et al, 2004; Trout et al, 2005; Abeywardena et al, 2012; Li et $a l, 2012)$.

Morphologically undistinguished $\mathrm{Gi}$ ardia parasites can be assigned to eight distinct assemblages (A to $\mathrm{H}$ ) based on enzymatic and molecular studies (Monis et al, 2003; Wielinga and Thompson, 2007). Available data showed that many Giardia lineages are highly hostspecific with $G$. duodenalis, assemblages $A$ and $B$ have the widest host ranges, infecting humans, domestic animals and livestock, and terrestrial wildlife (Thompson et al, 2000), and marine mammals and birds (Lasek-Nesselquist et al, 2008). Other G. duodenalis asse- mblages have more restricted host ranges as assemblage $\mathrm{E}$ associated with hoofed livestock (O'Handley et al, 2000; Trout et al, 2005), assemblages $\mathrm{C}$ and $\mathrm{D}$ typically isolated from dogs, assemblages $\mathrm{F}$ and $\mathrm{G}$ infecting cats and rodents, respectively (Monis et al, 2003). Assemblage $\mathrm{H}$ was isolated from marine vertebrates (Feng and Xiao, 2011). Assemblage-associated differences in the pathogenesis and clinical outcome have been reported both in clinical cases (Homan and Mank, 2001; Read et al, 2002; Sahagun et al, 2008; Breathnach et al, 2010; Ignatius et al, 2012) and experimental models (Solaymani-Mohammadi and Singer, 2011; Koh et al, 2012).

Although giardiasis is very common in Egypt (Zaki et al, 1986; Bakr et al, 2009; Baiomy et al, 2010; Mousa et al, 2010; Badawy et al, 2012) limited studies have been done on the molecular characterization of the parasite so far (Foronda et al, 2008; Soliman et al, 2011). El-Shazly et al. (2004) determined Giardia genotypes by using sequence differences at triosephosphate isomerase (tip) gene locus divide Giardia into three groups. The groups 1, 2 \& 3 were assigned by restriction fragment length polymorphism (RFLP) of PCR-amplified DNA extracted from the original stool samples of the parasitologic proved patients with Giardia. But, extensive farming practices in the Nile Delta address the public health problem concerns possible of zoonotic transmission.

The present study aimed at demonstration the molecular identity of $G$. duodenalis derived from human iso- 
lates, at Kafr El Sheikh Governorate, based on PCR-sequence analysis of triose phosphate isomerase (TPI) gene. The study also extended to ascertain isolates from the nearby farms in order to assess the potential zoonotic transmission and possible implications to public health.

\section{Materials and Methods}

The approach of collecting sporadic clinical cases, from infected human and naturally infected calves was adopted in the present study to cover a wide range of possible heterogeneity rather than one point prevalence which might be biased to certain genotype circulate in certain group under study. A total of 48 positive isolates were collected during January-September 2010 from the commercial medical laboratories at Kafr El Sheikh (130 Km North West of Cairo). The samples were obtained after the consent of the patient. Also, 18 positive samples were obtained from neonatal calves (1-8 weeks old) from dairy farm cattle in the same study area. Positive samples were stored at $4{ }^{\circ} \mathrm{C}$ in potassium dichromate until molecularly analyzed.

DNA extraction: Positive samples were washed off dichromate with double distilled water. Washed samples were processed as previously described (Amer et al, 2009) and DNA was extracted using QIAamp ${ }^{\circledR}$ DNA Stool Kit (Qiagen, Maryland, USA), following the manufacturer's instructions.

PCR amplification: Genotyping was done by amplification of a fragment $(\sim$ $530 \mathrm{bp}$ ) from triophosphate isomerase (TPI) gene by nested PCR following previous described protocols (Sulaiman et al, 2003). Briefly, PCR was done in $50 \mu 1$ reaction volume utilizing $1 \mu \mathrm{l}$ of the extracted DNA $(2 \mu 1$ primary PCR product for the $2^{\text {nd }} \mathrm{PCR}$ ) as template. The reaction mixture contained $200 \mathrm{nM}$ of the forward and reverse primers, 200 $\mathrm{mM}$ dNTPs, $3.0 \mathrm{mM} \mathrm{MgCl} 2,10 \%(\mathrm{v} / \mathrm{v})$ PCR buffer, $0.5 \mathrm{U}$ Taq polymerase and $\mathrm{H}_{2} \mathrm{O}$ to a total volume of $50 \mu 1$. PCR was done under the conditions of $94^{\circ} \mathrm{C}$ for $5 \mathrm{~min}$ to denature the template DNA, followed by 35 cycles of $45 \mathrm{~s}$ at $95^{\circ} \mathrm{C}, 45 \mathrm{~s}$ at $50^{\circ} \mathrm{C}\left(54^{\circ} \mathrm{C}\right.$ for the $2^{\text {nd }}$ PCR) and $1 \mathrm{~min}$ at $72^{\circ} \mathrm{C}$. A final step of $10 \mathrm{~min}$ at $72^{\circ} \mathrm{C}$ was included. Secondary PCR products were electrophoresed on $1.5 \%$ agarose gel and visualized after staining with ethidium bromide.

DNA Sequencing: Secondary PCR products were purified using Exonuclease I/Shrimp Alkaline Phosphatase (Exo-SAP-IT TM, USB, Cleveland, OH, USA). Purified products were sequenced using the $2^{\text {nd }}$ PCR primers in $20 \mu \mathrm{l}$ reaction volume using Big Dye ${ }^{\circledR}$ Terminator v3.1 Cycle Sequencing Kit (Applied Bio-systems Japan Ltd., Tokyo, Japan) on an automated sequencer (Applied Biosystems 3130xl Genetic Analyzer; Applied Biosystems Japan Ltd.). The accuracy of data was confirmed by two-directional sequencing.

For phylogenetic analysis sequences were aligned using Clustal X software, and phylogeny was inferred by Maximum Likelihood and Maximum Parsimony methods as implemented in the MEGA5 software (Tamura et al, 2011).

Nucleotide sequence accession numbers: Nucleotide sequence data report- 
ed here will appear in DDBJ/EMBL/ Gene-Bank nucleotide sequence.

\section{Results}

Triophosphate isomerase (TPI) gene is a polymorphic gene providing a good target for analyzing and genotyping Giardia (Wielinga and Thompson, 2007; Caccio and Ryan, 2008). A total of 48 human-derived Giardia isolates and 18 animal-derived ones were successfully amplified (Fig. 1) and subsequently sequenced. Alignment of the generated sequences revealed noticeable intra-sequence variations in form of nucleotide substitutions and no deletions or insertions were observed. Results showed that sequences generated from human isolates belong to assemblage $\mathrm{A}$ in 16 sequences and assemblage $\mathrm{B}$ in 32 sequences. Intra-variation showed that isolates of assemblage A arranged in 3 different sequence types; whereas isolates of assemblage B generated 11 different sequences. Two genotypes were identified in calves-derived isolates, assemblage $\mathrm{A}$ in 4 sequences and assemblage $\mathrm{E}$ in 14 sequences. All calves' sequences of assemblage A were identical but different than those generated from human isolates, whereas assemblage E showed 4 different types of sequences.

Blast search revealed high similarity of the generated sequences with the corresponding ones in the Gene-bank (99-100\%). Also, analysis of the phylogenetic trees inferred using the Maximum likelihood method were done to show the relationship of the generated sequences with reference ones of the corresponding assemblages (Fig. 2), as well as with reference sequences belonging to other assemblages (Fig. 3).

The generated sequences with the corresponding references were separated into 3 monophyletic groups; each clade was subdivided into subclades refereeing to sequence variation (Fig. 2). The first category included all sequences belong to assemblage A, with sequences KF-H17 \& KF-H19 clustered with other sequences belonging to subassemblage AII including AY368157 and EU518562 derived from waste water, USA and herring gull (Larus argentatus) from Canada, respectively. They showed high similarity with sequences AB569403 \& AB516351from human from Japan and GQ444449 from lamb in Australia (99-100\% identity). AI sub-assemblage occupied a separate branch with high bootstrap value (88) sequence KF-C8 derived from neonatal calf and JF792423 from sheep in Spain and EU518565 from herring gull (L. argentatus) from Canada and GU564274 from human in China. Interestingly, human-derived sequence KF-H21 clearly separated from all other sequences (99) indicating the uniqueness of this sequence. In non-zoonotic assemblage E, 3 sister groups were displayed on the tree with sequence KF-C6 and KF-C7 cluster with EU189331isolated from goat in Spain; sequence KF-C1 group with AY655705 and KF-C3 assembled with that AY655706 from neonatal calves in USA.

In the third clade, Assemblage B, sequence KF-H1, KF-H5, KF-H10 and KF-H12 assembled with sequence JF918463 derived from human in In- 
dia, with KF-H5, KF-H10 more related to each other (bootstrap 50). The clustering pattern indicates that sequences KF-H3, KF-H6, KF-H4, KF-H13, KFH9, KF-H8 and KF-H7 form a separate subclade with sequence JQ863254 derived from wastewater in China and AY368170 derived from wastewater in USA, with subsequent subdivision indicating intra-sequence variation.

In reference of relationship of obtained sequences with other Giardia assemblages (Fig. 3) ML was constructed using known reference assemblages' sequences in the database and G. muris as outgroup. The resultant tree formed 2 clear clades, the first one include assemblages $\mathrm{A}, \mathrm{E} \& \mathrm{~F}$, whereas assemblages $\mathrm{B}, \mathrm{D}, \mathrm{C} \& \mathrm{G}$ are more related and clustered in one clade. Also, the tree revealed that assemblage $\mathrm{E}$ $\& \mathrm{~F}$ are more close and separate from assemblage A with high bootstrap value (bootstrap 88). Assemblages C \& D are more related and assemblage $G$ is clearly separated from assemblage B, in spite of the low bootstrap values. The generated sequences keep their relative positions in the corresponding assemblages with minor modifications than that described (Fig. 2). The five sequences generated from human isolates (one sequence type (KF-H21) belongs to assemblage $\mathrm{A}$ and 4 sequence types (KF-H6, KF-H7, KF-H10 \& KFH19) belong to assemblage $B$ and the 4 sequence types belong to assemblage $\mathrm{E}$ proved to be novel sequences not reported in Gene-bank before.

\section{Discussion}

Molecularly, G. intestinalis has been divided into several assemblages and sub-assemblages that differ in the virulence and clinical outcome (SolaymaniMohammadi and Singer, 2011; Ignatius et al, 2012; Koh et al, 2012). In Egypt, giardiasis is very common disease (Zaki et al, 1986; Bakr et al, 2009; Baiomy et al, 2010; Mousa et al, 2010; Badawy et al, 2012), with little background on molecular level (Foronda et al, 2008; Soliman et al, 2011). Kafr El Sheikh Governorate is a rural province with extensive animal farm practices creating situation likely favor the transmission from human to animals or vice versa (Traub et al, 2004).

In the present study, analysis of 48 sporadic human cases generated 14 different sequence types assembled into 2 assemblages A and B. Assemblage A accounted for $16 / 48(33.3 \%)$ and assemblage B accounted for $32 / 48$ $(66.7 \%)$ of the generated sequences. These results are corroborating with those reported by Boontanom et al. (2011) and Ferreira et al. (2012). On the other hand, Gelanew et al. (2007) reported predominance of assemblage A over B in clinical samples from Ethiopia, whereas Souza et al. (2007) and Yang et al. (2010) reported all analyzed isolates from Brazil and Australia were exclusively belonged to assemblage In Egypt, Foronda et al. (2008) and Soliman et al. (2011) reported 1/18 and $1 / 15$ as assemblage $\mathrm{A} / \mathrm{B}$. The relatively high proportion of assemblage A in the present study might be attributed to rural nature of Kafr El Sheikh City and the frequent contact with farm animals which may favor zoonotic transmission (Traub et al, 2004). In this re- 
gard, it is reported that the host distribution of assemblage $\mathrm{B}$ is predominantly human and to a much lesser extent to other animals (Winkworth et al, 2008; Sprong et al, 2009; Lim et al, 2012). The factors responsible to the high occurrence of assemblage B over A linage are still obscure. Also, Kohli et al. (2008) found that assemblage B has a high cyst excretion pattern that facilitated oral-fecal transmission and contributed to make genotype $\mathrm{B}$ the most prevalent with the highest dispersion.

In spite of intra-sequence variation, assemblage A sequences retrieved from clinical samples were assigned to subassemblage AI and AII. Results of previous studies in various areas have shown that humans are mostly infected with AII, although AI is also seen in some areas or studies (Sahagun et al, 2008; Xiao and Fayer, 2008). However, there is still debate about the anthroponotic and zoonotic potential of assemblage A infections in dairy cattle (Mark-Carew et al, 2012).

The present results revealed that assemblage E was the predominant genotype (14/18: 77.8\%), whereas assemblage A showed low occurrence (4/18: $22.2 \%$ ). These results are in agreement with those reported from dairy cattle (Thompson and Monis 2004; Trout et al. 2004; Abeywardena et al, 2012; Mark-Carew et al, 2012), in beef cattle (Santin et al, 2012), sheep (Becher et al, 2004; Hunter and Thompson 2005; Ryan et al, 2005; Trout et al, 2005; Robertson et al, 2010), and goat (Ruiz et al, 2008; Lim et al, 2012). On the contrary, Santin et al. (2009) detected only assemblage $\mathrm{E}$ in cattle to 18 weeks of age in USA. Besides, predominance of assemblage A over $\mathrm{E}$ was reported in lambs in Spain (Gomez-Munoz et al, 2012). Assemblage A sequences derived from calves' isolates of the present study belongs to sub-assemblage AI. These findings agreed with Caccio and Ryan (2008), Xiao and Fayer (2008) and Sprong et al. (2009) that subassemblage AI is preferentially found in livestock and to lesser extent in other animals (Li et al, 2012). However, this sub-assemblage still has the potential zoonotic transmission to human (Xiao and Fayer, 2008).

The present results showed high degree of heterogeneity in the form of nucleotide substitutions resulted in high number of different sequences. Similar findings were reported by Li et al. (2012), Zhang et al. (2012). In this regard, several explanations were in debate including recombination/genetic exchange between homologous loci from different assemblages was identified in at least three G. duodenalis isolates (Lasek-Nesselquist et al, 2009) or the same assemblage (Takumi et al, 2012). Also, heterozygosity played important role in the sequence variation (Ankarklev et al, 2012).

Notably, it is well established that assemblage $\mathrm{E}$ is not zoonotic genotype of G. intestinalis (Thompson, 2003). But, Foronda et al. (2008) reported assemblage $\mathrm{E}$ in $15 \%$ of the clinical samples from Egypt, the observation not reported anywhere else till now. In conclusion, results reported herein indicate that pre-weaned calves still act as res- 
ervoir for zoonotic infection of $G$. intestinalis assemblage $\mathrm{A}$, and may have public health concerns.

\section{Acknowledgement}

This study was supported in part by Kafr El Sheikh University. The author would like to express deep thanks to all laboratory members and patients as well as all farm owners who kindly in one way or another facilitated this present study.

\section{References}

Abeywardena, H, Jex, A, Nolan, M, Haydon, S, Stevens, M, et al, 2012: Genetic characterization of Cryptosporidium and Giardia from dairy calves: Discovery of species/genotypes consistent with those found in humans. Infect. Genet. Evol. 12:1984-93.

Aloisio, F, Filippini, G, Antenucci, P, Lepri, E, Pezzotti, G, et al, 2006: Severe weight loss in lambs infected with Giardia duodenalis assemblage B. Vet. Parasitol. 30, 142:154-8.

Amer, S, Honma, H, Ikarashi, M, Oishi, R, Endo, M, et al, 2009: The first detection of Cryptosporidium deer-like genotype in cattle in Japan. Parasitol. Res. 104:745-52.

Ankarklev, J, Svard, S, Lebbad, M, 2012: Allelic sequence heterozygosity in single Giardia parasites. BMC Microbiol. 12:65-70.

Badawy, A, Gneidy, M, Ghoniemy, A, 2012: Acute diarrhea among military recruits. J. Egypt. Soc. Parasitol. 42:309-20.

Baiomy, A, Mohamed, K, Ghannam, M, Shahat, S, Al-Saadawy, A, 2010: Opportunistic parasitic infections in immunocompromised Egyptian patients. J. Egypt. Soc. Parasitol. 40:797-808.

Bakr, I, Arafa, N, Ahmed, M, Mostafa, Mel, H, Mohamed, M, 2009: Prevalence of intestinal parasitosis in a rural population in Egypt and its relation to sociodemographic characteristics. J. Egypt. Soc. Parasitol. 39:371-81.

Becher, K, Robertson, I, Fraser, D, Palmer, D, Thompson, R, 2004: Molecular epidemiology of Giardia and Cryptosporidium infections in dairy calves originating from three sources in Western Australia. Vet. Parasitol. 123: 1-9.

Boontanom, P, Mungthin, M, TanAriya, P, Naaglor, T, Leelayoova, S, 2011: Epidemiology of giardiasis and genotypic characterization of Giardia duodenalis in preschool children of a rural community, central Thailand. Trop. Biomed. 28:32-9.

Breathnach, A, McHugh, T, Butcher, P, 2010: Prevalence and clinical correlations of genetic subtypes of Giardia lamblia in an urban setting. Epidemiol. Infect. 138:1459-67.

Buret, A, 2008: Pathophysiology of enteric infections with Giardia duodenalis. Parasite 15:261-5.

Caccio, S, Ryan, U, 2008: Molecular epidemiology of giardiasis. Mol. Biochem. Parasitol. 160:75-80.

Chin, A, Teoh, D, Scott, K, Meddings, J, Macnaughton, W, et al, 2002: Strain-dependent induction of enterocyte apoptosis by Giardia lamblia disrupts epithelial barrier function in a caspase-3-dependent manner. Infect. Immun. 70: 3673-80. 
Cotton, J, Beatty, J, Buret, A, 2011: Host parasite interactions and pathophysiology in Giardia infections. Int. J. Parasitol.41: 925-33.

El-Shazly, AM, Mowafy, N, Soliman, M, El-Bendary, M, Morsy, ATA, et al, 2004: Egyptian genotyping of Giardia lamblia. J. Egypt. Soc. Parasitol. 34, 1:265-80.

Feng, Y, Xiao, L, 2011: Zoonotic potential and molecular epidemiology of Giardia species and giardiasis. Clin. Microbiol. Rev. 24:110-40

Ferreira, F, Centeno-Lima, S, Gomes, J, Rosa, F, Rosado, V, et al, 2012: Molecular characterization of Giardia duodenalis in children from the Cufada Lagoon Natural Park, Guinea-Bissau. Parasitol. Res.111: 2173-27.

Foronda, P, Bargues, M, Abreu-Acosta, N, Periago, M, Valero, M, et al, 2008: Identification of genotypes of Giardia intestinalis of human isolates in Egypt. Parasitol. Res. 103:1177-81.

Fraser, D, Bilenko, R, Deckelbaum, R, Dagan, J, el-On, J, et al, 2000: $G i-$ ardia lamblia carriage in Israeli Bedouin infants: risk factors and consequences. Clin. Infect. Dis. 30:419-24.

Gelanew, T, Lalle, M, Hailu, A, Pozio, E, Caccio, S, 2007: Molecular characterization of human isolates of $\mathrm{Gi}$ ardia duodenalis from Ethiopia. Acta Trop. 102:92-9.

Gomez-Munoz, M, Camara-Badenes, C, Martinez-Herrero, C, Dea-Ayuela, M, et al, 2012: Multilocus genotyping of Giardia duodenalis in lambs from Spain reveals a high heterogeneity. Res. Vet. Sci. 93:836-42.
Heresi, G, Cleary, T, 1997: Giardia. Pediatr. Rev.18:243-7.

Homan, W, Mank, T, 2001: Human giardiasis: genotype linked differences in clinical symptomatology. Int. J. Parasitol. 31:822-6.

Hunter, P, Thompson, R, 2005: The zoonotic transmission of Giardia and Cryptosporidium. Int. J. Parasitol. 35: 1181-90.

Ignatius, R, Gahutu, J, Klotz, C, Steininger, C, Shyirambere, C, et al, 2012: High Prevalence of Giardia duodenalis assemblage B infection and association with underweight in Rwandan Children. PLoS. Negl. Trop. Dis. 6:e1677.

Karanis, P, Kourenti, C, Smith, H, 2007: Waterborne transmission of protozoan parasites: a worldwide review of outbreaks and lessons learnt. J. Water Hlth. 5:1-38.

Koh, W, Geurden, T, Paget, T, $\mathbf{O}^{\prime}$ Handley, R, Steuart, R, et al, 2012: Giardia duodenalis assemblage-specific induction of apoptosis and tight junction disruption in human intestinal epithelial cells: Effects of mixed infections. J. Parasitol. In Press.

Kohli, A, Bushen, O, Pinkerton, R, Houpt, E, Newman, R, et al, 2008: Giardia duodenalis assemblage, clinical presentation and markers of intestinal inflammation in Brazilian children. Trans, R. Soc. Trop. Med. Hyg. 102: 718-25.

Lasek-Nesselquist, E, Bogomolni, A, Gast, R, Welch, D, Ellis, J, et al, 2008: Molecular characterization of Giardia intestinalis haplotypes in ma- 
rine animals: Variation and zoonotic potential. Dis. Aquat. Orga. 81:39-51.

Lasek-Nesselquist, E, Welch, D, Thompson, R, Steuart, R, Sogin, M, 2009: Genetic exchange within and between assemblages of Giardia duodenalis. J. Eukaryot. Microbiol. 56: 504-518.

\section{Li, J, Zhang, P, Wang, P, Alsarakibi,} M, Zhu, H, et al, 2012: Genotype identification and prevalence of Giardia duodenalis in pet dogs of Guangzhou, Southern China. Vet. Parasitol. 188: 368-71.

Li, N, Xiao, L, Wang, L, Zhao, S, Zhao, $\mathrm{X}$, et al, 2012: Molecular surveillance of Cryptosporidium spp., Giardia duodenalis, and Enterocytozoon bieneusi by genotyping and subtyping parasites in wastewater. PLoS. Negl. Trop. Dis. 6:e1809.

Lim, Y, Mahdy, M, Tan, T, Goh, X, Jex, A, et al, 2012: First molecular characterization of Giardia duodenalis from goats in Malaysia. Mol. Cell. Probes 27:28-31.

Mark-Carew, M, Wade, S, Chang, Y, Schaaf, S, Mohammed, H, 2012: Prevalence of Giardia duodenalis assemblages among dairy herds in the New York City Watershed. Vet. Parasitol. 185:151-7.

Mehraj, V, Hatcher, J, Akhtar, S, Rafique, G, Beg, M, 2008: Prevalence and factors associated with intestinal parasitic infection among children in an urban slum of Karachi. PLoS. One 3: e3680.

Monis, P, Andrews, R, Mayrhofer, G, Ey, P, 2003: Genetic diversity with- in the morphological species Giardia intestinalis and its relationship to host origin. Infect. Genet. Evol. 3:29-38.

Mousa, K, Abdel-Tawab, A, Khalil, H, El-Hussieny, N, 2010: Diarrhea due to parasites particularly Cryptosporidium parvum in great Cairo, Egypt. J. Egypt. Soc. Parasitol. 40:439-50.

O'Handley, R, Olson, M, Fraser, D, Adams, P, Thompson, R, 2000: Prevalence and genotypic characterization of Giardia in dairy calves from Western Australia and Western Canada. Vet. Parasitol. 90:193-200.

Plutzer, J, Ongerth, J, Karanis, P, 2010: Giardia taxonomy, phylogeny and epidemiology: Facts and open questions. Int. J. Hyg. Environ. Hlth. 213: 321-33.

Read, C, Walters, J, Robertson, I, Thompson, R, 2002: Correlation between genotype of Giardia duodenalis \& diarrhea. Int. J. Parasitol. 32:229-31.

Robertson, L, Gjerde, B, Hansen, E, 2010: The zoonotic potential of Giardia and Cryptosporidium in Norwegian sheep: a longitudinal investigation of 6 flocks of lambs. Vet. Parasitol. 171: 140-5.

Ryan, U, Bath, C, Robertson, I, Read, C, Elliot, A, et al, 2005: Sheep may not be an important zoonotic reservoir for Cryptosporidium and Giardia parasites. Appl. Environ. Microbiol. 71:4992-7.

Sahagun, J, Clavel, A, Goni, P, Seral, C, Llorente, M, et al, 2008: Correlation between the presence of symptoms and the Giardia duodenalis genotype. Eur. J. Clin. Microbiol. Infect. Dis. 
27: 81-3.

Santin, M, Dargatz, D, Fayer, R, 2012: Prevalence of Giardia duodenalis assemblages in weaned cattle on cow-calf operations in the United States. Vet. Parasitol. 183:231-6.

Santin, M, Trout, J, Fayer, R, 2009: A longitudinal study of Giardia duodenalis genotypes in dairy cows from birth to 2 years of age. Vet. Parasitol. 162: 40-5.

Santos, C, Grama, D, Limongi, J, Costa, F, Couto, T, et al, 2012: Epidemiological, parasitological and molecular aspects of Giardia duodenalis infection in children attending public daycare centers in southeastern Brazil. Trans R. Soc. Trop. Med. Hyg. 106: 473-9.

Savioli, L, Smith, H, Thompson, A, 2006: Giardia and Cryptosporidium join the 'neglected diseases initiative'. Trends Parasitol. 22:203-8.

Solaymani-Mohammadi, S, Singer, S, 2011: Host immunity and pathogen strain contribute to intestinal disaccharidase impairment following gut infection. J. Immunol. 187:3769-75.

Soliman, R, Fuentes, I, Rubio, J, 2011: Identification of a novel Assemblage B subgenotype and a zoonotic Assemblage $\mathrm{C}$ in human isolates of Giardia intestinalis in Egypt. Parasitol. Int. 60:507-11.

Souza, S, Gennari, S, Richtzenhain, L, Pena H, Funada, M, et al, 2007: Molecular identification of Giardia duodenalis isolates from humans, dogs, cats and cattle from the state of Sao Paulo, Brazil, by sequence analysis of fragments of glutamate dehydrogenase (gdh) coding gene. Vet. Parasitol. 149: 258-64.

Sprong, H, Caccio, S, Van der Giesen, J, 2009: Identification of zoonotic genotypes of Giardia duodenalis. PLoS. Negl. Trop. Dis. 3:e558.

Sulaiman, I, Fayer, R, Bern, C, Gilman, R, Trout, J, et al, 2003: Triosephosphate isomerase gene characterization and potential zoonotic transmission of Giardia duodenalis. Emerg. Infect. Dis. 9:1444-52.

Takumi, K, Swart, A, Mank, T, Lasek-Nesselquist, E, Lebbad, $M$, et al, 2012: Population-based analyses of $G i$ ardia duodenalis is consistent with the clonal assemblage structure. Parasite Vector 5:168.

Tamura, K, Nei, M, 1993: Estimation of the number of nucleotide substitutions in the control region of mitochondrial DNA in humans and chimpanzees. Mol. Biol. Evol. 10:512-26.

Tamura, K, Peterson, D, Peterson, N, Stecher, G, Nei, M, et al, 2011: MEGA5: molecular evolutionary genetics analysis using maximum likelihood, evolutionary distance, and maximum parsimony methods. Mol. Biol. Evol. 28:2731-9.

Thompson, R, 2000: Giardiasis as a reemerging infections disease and its zoonotic potential. Int. J. Parasitol. 30: 1259-67.

Thompson, R, 2001: Human giardiasis: Genotype-linked differences in clinical symptomatology. Trends Parasitol. 17:465-72. 
Thompson, R, 2003: Molecular epidemiology of Giardia and Cryptosporidium infections. J. Parasitol. 89:S13440.

Thompson, R, 2004: The zoonotic significance and molecular epidemiology of Giardia and giardiasis. Vet. Parasitol. 126:15-35

Thompson, R, Monis, P, 2004: Variation in Giardia: implications for taxonomy and epidemiology. Adv. Parasitol. 58:69-137.

Thompson, R, Palmer, C, O'Handley, R, 2008: The public health and clinical significance of Giardia and Cryptosporidium in domestic animals. Vet. J. 177:18-25.

Thompson, R, Smith, A, 2011: Zoonotic enteric protozoa. Vet. Parasitol. 182:70-8.

Tien, J, Earn, D, 2010: Multiple transmission pathways and disease dynamics in a waterborne pathogen model. Bull. Math. Biol. 72:1506-33.

Traub, R, Monis, P, Robertson, I, Irwin, P, Mencke, N, et al, 2004: Epidemiological and molecular evidence supports the zoonotic transmission of Giardia among humans and dogs living in the same community. Parasitol. 128: 253-62.

Troeger, H, Epple, H, Schneider, T, Wahnschaffe, U, Ullrich, R, et al, 2007: Effect of chronic Giardia lamblia infection on epithelial transport and barrier function in human duodenum. Gut 56:328-35.

Trout, J, Santin, M, Greiner, E, Fayer, R, 2004: Prevalence of Giardia duodenalis genotypes in pre-weaned dai- ry calves. Vet. Parasitol. 124:179-86

Trout, J, Santin, M, Greiner, E, Fayer, R, 2005: Prevalence and genotypes of Giardia duodenalis in post-weaned dairy calves. Vet. Parasitol. 130:17783.

Wielinga, C, Thompson, R, 2007: Comparative evaluation of Giardia $d u$ odenalis sequence data. Parasitol. 134: 1795-821.

Winkworth, C, Learmonth, J, Matthaei, C, Townsend, C, 2008: Molecular characterization of Giardia isolates from calves and humans in a region in which dairy farming has recently intensified. Appl. Environ. Microbiol. 74: 5100-5.

Xiao, L, Fayer, R, 2008: Molecular characterization of species and genotypes of Cryptosporidium and Giardia and assessment of zoonotic transmission. Int. J. Parasitol. 38, 11:1239-55.

Yang, R, Lee, J, Ng, J, Ryan, U, 2010: High prevalence Giardia duodenalis assemblage B and potentially zoonotic subtypes in sporadic human cases in Western Australia. Int. J. Parasitol. 40:293-7.

Zaki, A, DuPont, H, El Alamy, M, Arafat, R, Amin, K, et al, 1986: The detection of enteropathogens in acute diarrhea in a family cohort population in rural Egypt. Amer. J. Trop. Med. Hyg. 35:1013-22.

Zhang W, Zhang X, Wang R, Liu, A, Shen, Y, et al, 2012: Genetic characterizations of Giardia duodenalis in sheep and goats in Heilongjiang Province, China and possibility of zoonotic transmission. PLoS. Negl. Trop. Dis.

6, 9:e1826. 


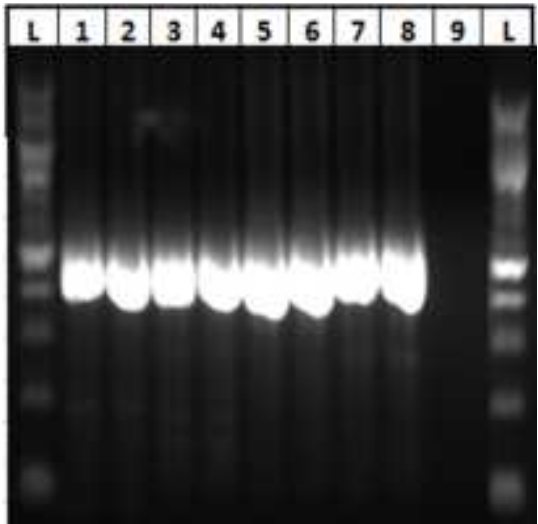

Fig. 1: PCR amplification of $\sim 530 \mathrm{bp}$ of TPI gene fragment. L, $100 \mathrm{bp}$ ladder; numbers of 1-8 correspond to test samples; lane no 9 refer to negative control. 


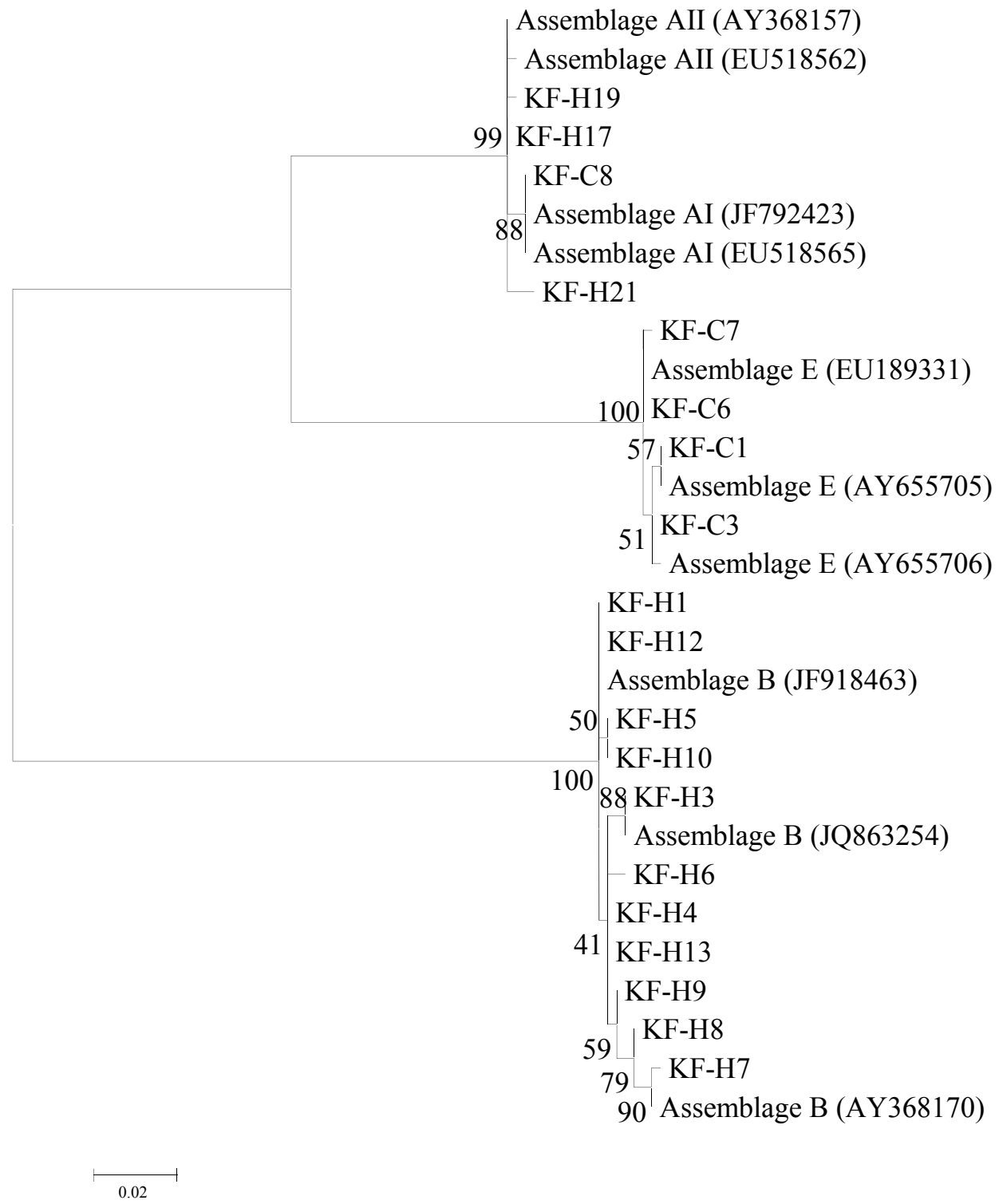

Fig. 2: Relationship of analyzed isolates to corresponding Giardia intestinalis assemblages based on sequences of the partial Triose Phosphate Isomerase (TPI) gene. Evolutionary relationships of 29 taxa inferred using Maximum Likelihood method (Tamura and Nei, 1993). Numbers at internodes correspond to percent bootstrap values from 2,000 replicates. Evolutionary distances computed using Maximum Composite Likelihood (MCL) method (Tamura et al., 2011). Tree unrooted. 


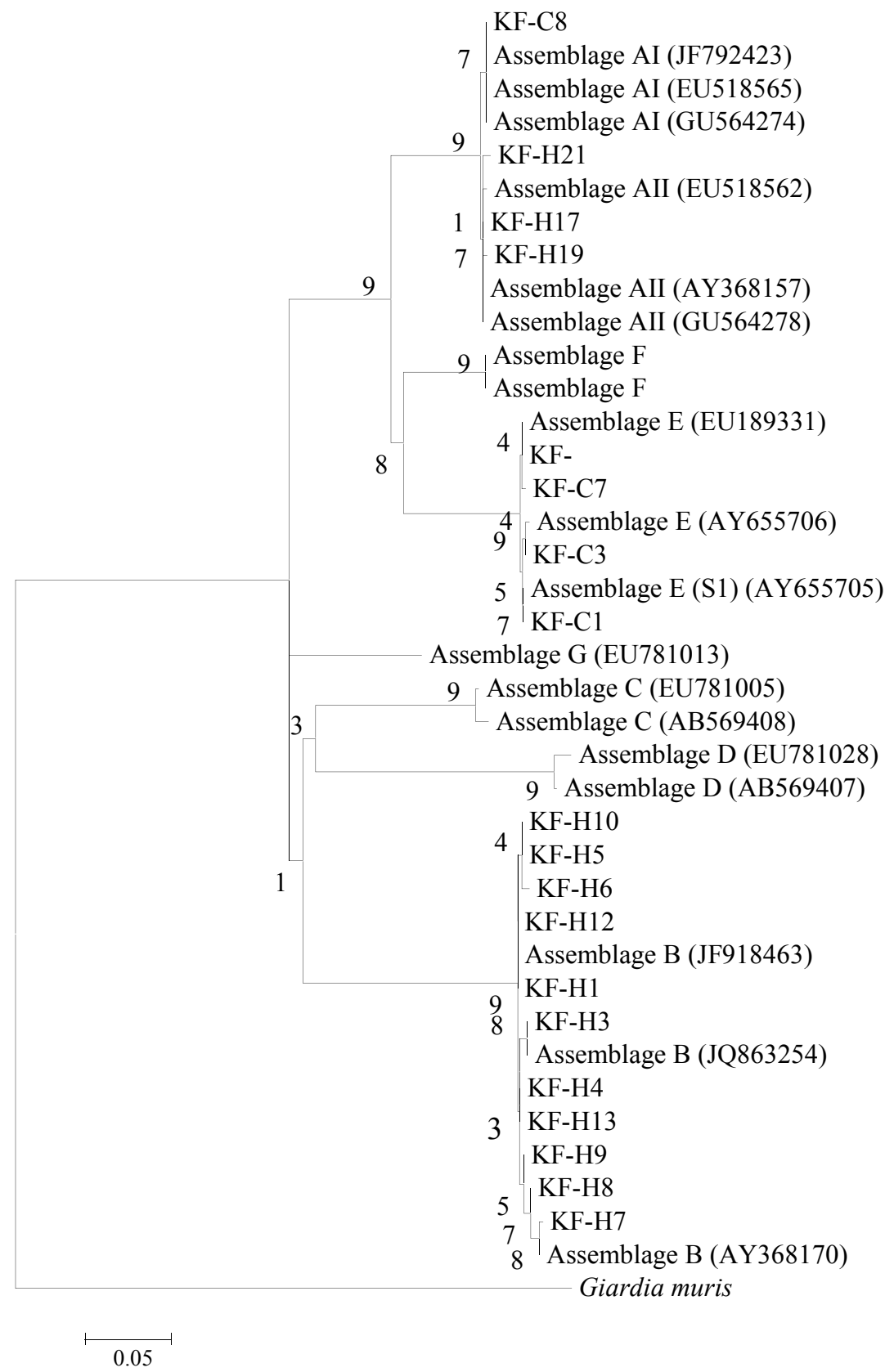

Fig. 3. Phylogenetic relationship Giardia intestinalis based on sequences of partial Triose Phosphate Isomerase (TPI) gene. Evolutionary relationships of 39 taxa were inferred using Maximum Likelihood method (Tamura and Nei, 1993). Numbers at internodes correspond to percent bootstrap values from 2,000 replicates. Evolutionary distances were computed using Maximum Composite Likelihood (MCL) method (Tamura et al, 2011). Giardia muris was used as outgroup. 